\title{
Prevalence of Bovine Brucellosis in Organized Dairy Farms, Using Milk ELISA, in Quetta City, Balochistan, Pakistan
}

\section{Muhammad Shafee, ${ }^{1}$ Masood Rabbani, ${ }^{2}$ Ali Ahmad Sheikh, ${ }^{2}$ Mansoor din Ahmad, ${ }^{3}$ and Abdul Razzaq ${ }^{4}$}

${ }^{1}$ University of Balochistan, Quetta, Balochistan, Pakistan

${ }^{2}$ University Diagnostic Laboratory, University of Veterinary and Animal Sciences, Lahore, Pakistan

${ }^{3}$ Department of Epidemiology and Public Health, University of Veterinary and Animal Sciences, Lahore, Pakistan

${ }^{4}$ Arid Zone Research Centre, Brewery Road, Quetta, Pakistan

Correspondence should be addressed to Muhammad Shafee, shafeegl@yahoo.com

Received 22 September 2010; Accepted 3 January 2011

Academic Editor: F. Mancianti

Copyright (C 2011 Muhammad Shafee et al. This is an open access article distributed under the Creative Commons Attribution License, which permits unrestricted use, distribution, and reproduction in any medium, provided the original work is properly cited.

A total of 200 milk samples from cattle $(n=86)$ and buffalo $(n=114)$ were evaluated using milk ring test (MRT) and indirect enzyme-linked immunosorbent assay (i-ELISA). The overall prevalence was found to be $3 \%$ and $8.5 \%$ in cattle and buffaloes using MRT and i-ELISA, respectively. The prevalence was $4.6 \%$ and $1.7 \%$ in cattle and buffalo using MRT, respectively, while iELISA exhibited $20 \%$ and $0 \%$ in cattle and buffalo, respectively. The prevalence was higher in government dairy farm, compared to privately owned dairy farm. This paper points out an alarming situation in the target area with respect to the public health significance.

\section{Introduction}

The livestock sector has emerged as a leading subsector of the agriculture over the years in Pakistan. Livestock production is one of the major activities, as about 30-35 million people of rural areas of Pakistan are engaged in raising livestock and deriving 30-40 percent of their income. It accounts for 53.2\% of the agriculture value added and $11.4 \%$ of the national GDP [1].

Brucellosis is a highly contagious, zoonotic, and economically important bacterial disease of animals worldwide [2]. It causes significant economic losses including abortion, loss in milk production, low fertility rates, and cost of replacement of animals [3].

It is the second most important zoonotic disease in the world after rabies [4]. The importance of this highly contagious disease is due to its severe hazards to human health, through either direct contact with infected animals or through consumption of contaminated milk and dairy products, and its economic impact on the animal industry, causing an adverse effect on animal health.
It is a significant public health problem in an agricultural country like Pakistan, where the vast majority of the population is involved in land cultivation and livestock farming.

The incidence of brucellosis in Pakistan is increasing particularly in large dairy herds. Earlier studies indicated lower prevalence, that is, $0.33 \%$ to $0.65 \%$ [5]. Whereas much higher prevalence is reported in some recent studies, that is, $21 \%$ to $26 \%$ [6]. The incidence is higher in animals kept at organized farms rather than small holdings [7].

It is a global problem of wild and domestic animals, especially cattle, sheep, and goats causing a decrease in reproductive efficacy and an increase in abortion rate [8]. It has also been reported in most of the developing countries, like Nigeria, where it prevails up to $13.5 \%$ indicating higher threat to human and animal health [9].

This study was designed to assess the prevalence of this infectious zoonotic disease in the target area and to create awareness among the inhabitants of the area. 


\section{Materials and Methods}

A total of 200 bovine milk samples were collected from government and privately owned organized dairy farms in Quetta City and subjected to milk ring test (MRT) and indirect ELISA for the detection of antibrucella antibodies.

2.1. Milk Ring Test (MRT). A drop ( $30 \mu \mathrm{l})$ of stained brucella antigen was added to $01 \mathrm{ml}$ of whole milk that has been kept at $4^{\circ} \mathrm{C}$ using overnight refrigeration. The test result was read after incubation for 1 hour at $37^{\circ} \mathrm{C}$. A positive reaction was indicated by a stained cream layer over white column of milk [6]

2.2. Enzyme-Linked Immunosorbent Assay (i-ELISA). The indirect ELISA (i-ELISA) kit for the detection of antibrucella antibodies was obtained from M/S Svanova, Sweden, and the procedure was followed as per manufacturer's procedure.

All the milk samples were centrifuged at $5000 \mathrm{rpm}$ for 5 minutes to remove the cream layer before use. About $100 \mu \mathrm{l}$ of sample dilution buffer was added to the control wells and $4 \mu \mathrm{l}$ of positive control serum and $4 \mu \mathrm{l}$ of negative control serum were added, respectively, to selected precoated antigen wells. Later, $100 \mu$ l of milk samples were added to selected wells. The plate was shaken thoroughly, sealed, and incubated at $37^{\circ} \mathrm{C}$ for one hour. The plate was rinsed 3 times with PBSTween buffer followed by addition of $100 \mu \mathrm{l}$ of horse reddish peroxidase (HRP) conjugate (prepared in $11.5 \mathrm{ml}$ PBS-Tween buffer diluted in distilled water) to each well and incubated at $37^{\circ} \mathrm{C}$ for one hour. The plates were again rinsed thrice, and $100 \mu \mathrm{l}$ substrate solutions (tetramethylbenzidine) were added to all the wells. Microtitration plate was incubated for 1015 minutes at room temperature. Finally, $50 \mu \mathrm{l}$ of stopping solution was added to each well. The optical densities (OD) of the control and test-sample wells were adjusted at $405 \mathrm{~nm}$ wavelength using an ELISA reader (Thermo Electron, Finland).

The interpretation of results was performed accordingly.

$$
\mathrm{PP}(\text { percent positivity })=\frac{\text { Test sample OD }}{\text { Positive control OD }} 100
$$

For milk samples, a PP value equal or more than 10 was taken as positive.

\section{Results and Discussion}

The data collected revealed high prevalence $(8.5 \%)$ of the disease in the area; this prevalence is higher than previously reported (3.97\%) positive cases in cattle and buffalo using Rose Bengal plate test (RBPT) and serum agglutination test (SAT) by FAQIR [10] who also reported the presence of brucellosis in cattle and buffalo in the same area after screening 680 animals.

The prevalence was recorded much higher in cattle than buffaloes, as, out of 200 milk samples, 17 samples were found positive, all from cattle. These findings are in agreement with those of Abbas and Aldeewan [11] who also reported a

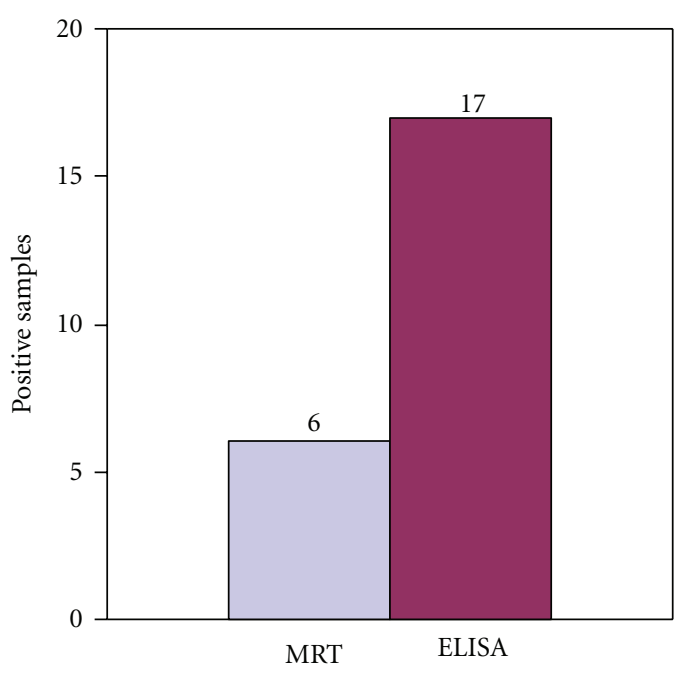

FIGURE 1: Graphical comparison of MRT with i-ELISA for detection of antibrucella antibodies in Milk Samples.

TABle 1: Prevalence of bovine brucellosis in milk samples using MRT and i-ELISA in District Quetta, Balochistan, Pakistan.

\begin{tabular}{lcc}
\hline \multirow{2}{*}{ Animal } & \multicolumn{2}{c}{ Positive samples } \\
& MRT & i-ELISA \\
\hline Cattle $n=86$ & $4(4.6 \%)$ & $17(20 \%)$ \\
Buffalo $n=114$ & $2(1.7 \%)$ & - \\
Percentage $n=200$ & $6 / 200(3 \%)$ & $17 / 200(8.5 \%)$ \\
\hline
\end{tabular}

MRT: milk ring test.

i-ELISA: indirect enzyme-linked immunosorbent assay.

higher prevalence of brucellosis in cattle $(10.5 \%)$ than that in buffalo (1.9\%). The higher prevalence in cattle may be attributed to the specie specificity or possibly the higher fat percentage in buffalo milk may be the obstacle in the detection of positive cases.

On farm comparison basis, the prevalence at governmentdairy farm (GDF) in Quetta was $14.8 \%$, as, out of 74 samples, 11 were found positive while the private dairy Farm (PDF) exhibited $4.76 \%$ prevalence, as, out of 126 milk samples, only 6 samples were positive (Table 2 ). This result is in agreement with the observations of Pederson [12] who reported higher prevalence among official herds than that of privately owned dairy farms. However, this result contradicts that of Naeem et al. [13] who reported higher prevalence of bovine brucellosis among privately owned animals.

The overall prevalence in organized dairy farms was 3\% by MRT, as 6 out of 200 samples were found positive while i-ELISA showed $8.5 \%$ prevalence, as 17 out of 200 milk samples were found positive (Table 1).

The indirect enzyme linked immunosorbent assay (iELISA) detected seventeen (17) milk samples whereas only 6 milk samples were detected positive by MRT indicating high sensitivity and specificity of i-ELISA than those of milk ring test. In the present study, the milk ELISA had detected more positive cases than MRT (Figure 1). These findings corroborate with Kerkhofs et al. [14], Vanzini et al. [15], and 
TABLE 2: Comparison of prevalence of brucellosis in government and privately owned dairy farms in Quetta city, Pakistan.

\begin{tabular}{lcccc}
\hline \multirow{2}{*}{ Animal species } & \multicolumn{2}{c}{ GDF $n=74$} & \multicolumn{2}{c}{ PDF $n=126$} \\
& \multicolumn{2}{c}{ Positive } & \multicolumn{2}{c}{ Positive } \\
& MRT & i-ELISA & MRT & i-ELISA \\
\hline Cattle $n=114$ & $0 / 74$ & 11 & $4 / 12$ & 6 \\
Buffalo $n=86$ & - & - & $2 / 114$ & 0 \\
Total $=200$ & $0 \%$ & $14.86 \%$ & $4.76 \%$ & $4.76 \%$ \\
\hline
\end{tabular}

PDF: private dairy farm.

GDF: government dairy farm.

MRT: milk ring test.

i-ELISA: indirect enzyme linked immunosorbent assay.

Kang' ethe et al. [16], who also reported milk ELISA as more sensitive than MRT.

\section{Conclusion}

The present study reflects much higher prevalence $(8.5 \%)$ of the disease in the target area. This is a serious threat to the public health and also to animal life. Most of the field workers, veterinarians, butchers, and milkmen are more prone to this disease. So, care should be taken while handling the suspected animal cases. Similarly, a large-scale survey should be done in the area to detect the carrier animals and should be treated according to the international rules. A large scale vaccination may also help to lower the prevalence of this disease; therefore, in larger dairy herds, vaccination may be helpful to overcome this problem. A large scale campaign through media may also be helpful to create awareness among people to use boiled or pasteurized milk to lower the risk of this human health problem.

\section{References}

[1] GOP (Government of Pakistan), Economic Survey 2009-2010.

[2] OIE, "Bovine brucellosis," in Manual of Standards for Diagnostic Tests and Vaccines, pp. 328-345, OIE, Paris, France, 4th edition, 2000.

[3] J. J. McDermott and S. M. Arimi, "Brucellosis in subSaharan Africa: epidemiology, control and impact," Veterinary Microbiology, vol. 90, no. 1-4, pp. 111-134, 2002.

[4] FAO, "Progress in understanding brucellosis," Vet Record. 641, 2003.

[5] S. A. Sheikh, M. A. Shah, and S. A. Khan, "Some observations on the incidence of brucellosis in West Pakistan," Pakistan Journal of Science, vol. 19, pp. 189-192, 1967.

[6] S. N. Sharma and S. C. Adlakha, Textbook of Veterinary Microbiology, vol. 192, Vikas Publishing House, New Delhi, India, 1997.

[7] R. Ahmad and M. A. Munir, "Epidemiological investigation of brucellosis in Pakistan," The Pakistan Veterinary Journal, vol. 15, pp. 169-172, 1995.

[8] N. P. Rijpens, G. Jannes, M. van Asbroeck, R. Rossau, and L. M. F. Herman, "Direct detection of Brucella spp. in raw milk by PCR and reverse hybridization with 16S-23S rRNA spacer probes," Applied and Environmental Microbiology, vol. 62, no. 5, pp. 1683-1688, 1996.
[9] W. J. Bertu, M. Dapar, A. M. Gusi, S. S. Ngulukun, S. Leo, and L. D. Jwander, "Prevalence of Brucella antibodies in marketed milk in Jos and environs," African Journal of Food Science, vol. 4, no. 2, pp. 062-064, 2010.

[10] FAQIR, Seroepidemiological survey of bovine brucellosis associated with reproductive disorders in Quetta district, Balochistan, M.S. thesis, Animal Reproduction, CVS, Lahore, Pakistan, 1991.

[11] B. A. Abbas and A. B. Aldeewan, "Occurrence and epidemiology of Brucella spp. in raw milk samples at Basrah province, Iraq," Bulgarian Journal of Veterinary Medicine, vol. 12, no. 2, pp. 136-142, 2009.

[12] C. H. Pederson, "A preliminary report on infertility among cattle and buffaloes in Punjab," Working paper 3, 1980, Pak. Vet. J.10 (4): 552.

[13] K. Naeem, S. Akhtar, and N. Ullah, "The serological survey of bovine brucellosis in Rawalpindi and Islamabad," The Pakistan Veterinary Journal, vol. 10, no. 4, pp. 154-156, 1990.

[14] P. Kerkhofs, Y. Botton, P. Thiange, P. Dekeyser, and J. N. Limet, "Diagnosis of bovine brucellosis by enzyme immunoassay of milk," Veterinary Microbiology, vol. 24, no. 1, pp. 73-80, 1990.

[15] V. R. Vanzini, N. P. Aguirre, B. S. Valentini et al., "Comparison of an indirect ELISA with the Brucella milk ring test for detection of antibodies to Brucella abortus in bulk milk samples," Veterinary Microbiology, vol. 82, no. 1, pp. 55-60, 2001.

[16] E. K. Kang'ethe, S. M. Arimi, A. O. Omore et al., "The prevalence of antibodies to Brucella abortus in marketed milk in Kenya and its public health implications," in Proceedings of the the 3rd All Africa Conference on Animal Agriculture, November 2000. 

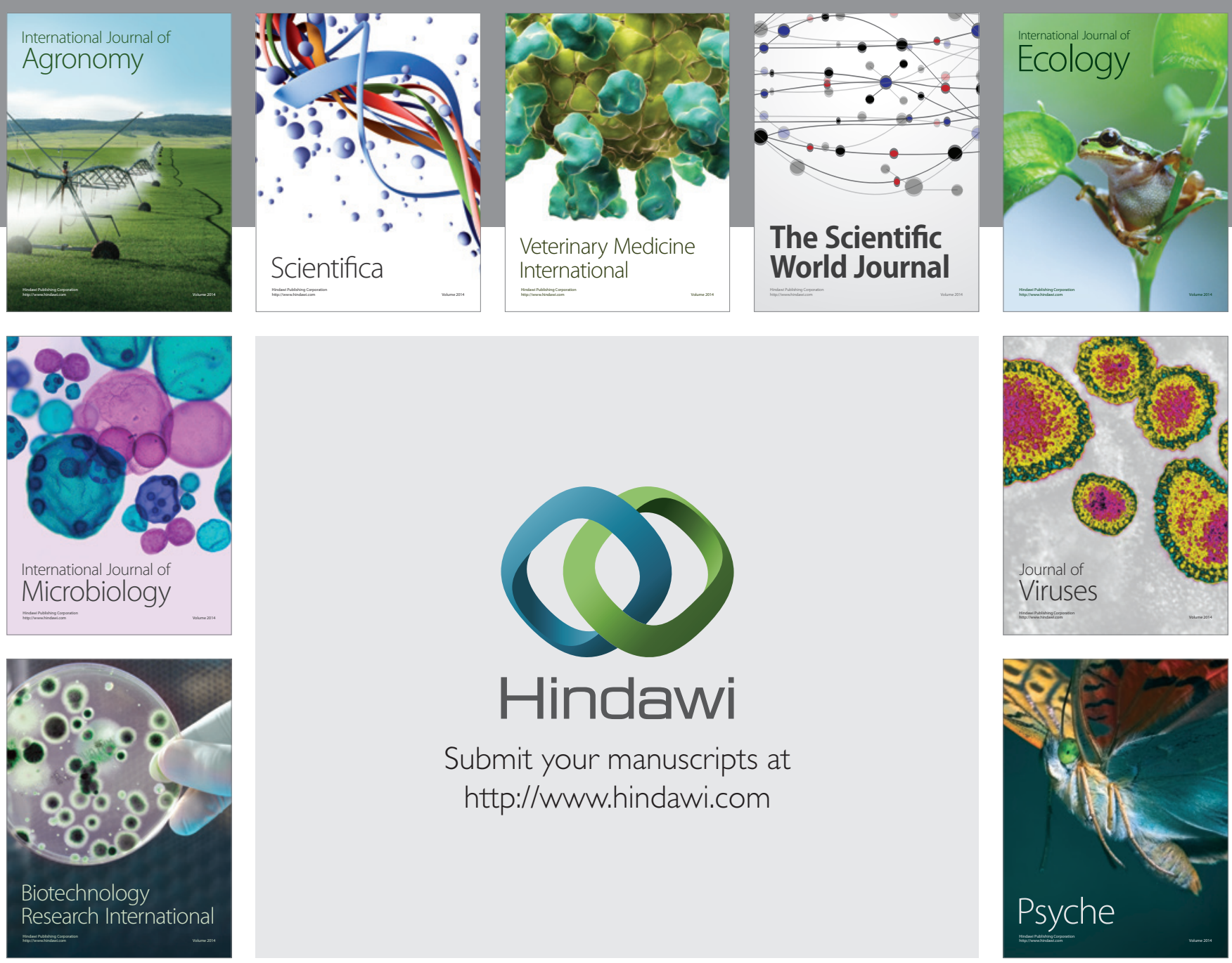

Submit your manuscripts at

http://www.hindawi.com
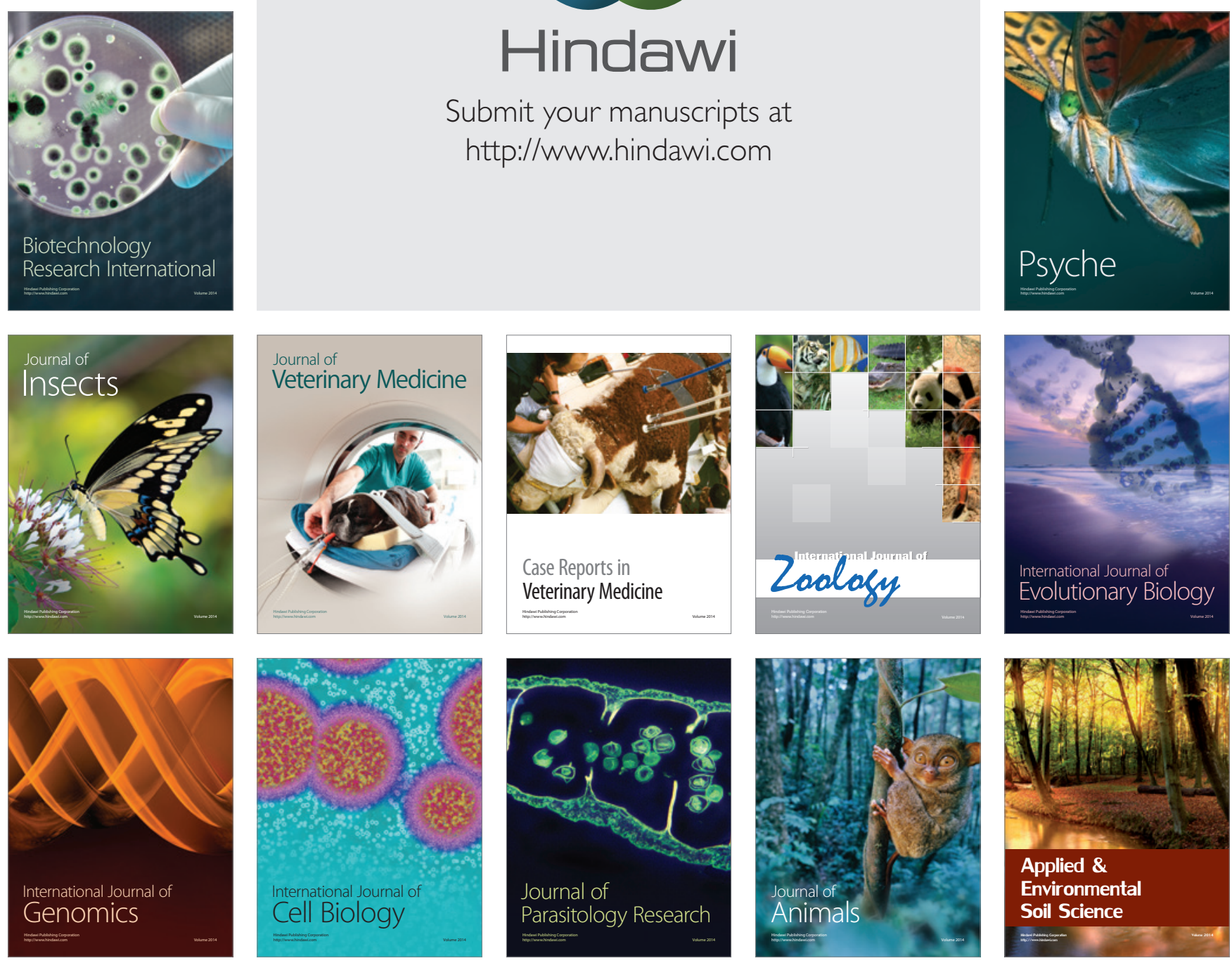